Published as: Gastroenterology2013 March ; 144(3): 636-649.e6.

\title{
Central Melanin-Concentrating Hormone Influences Liver and Adipose Metabolism Via Specific Hypothalamic Nuclei and Efferent Autonomic/JNK1 Pathways
}

\author{
Monica Imbernon ${ }^{1,2,{ }^{*}, \text { Daniel Beiroa }}{ }^{1,2,{ }^{*}, \text { María J. Vázquez }}{ }^{1,2}$, Donald A. Morgan ${ }^{3}$, Christelle \\ Veyrat-Durebex $^{4}$, Begoña Porteiro ${ }^{1,2}$, Adenis Díaz-Arteaga ${ }^{1,2}$, Ana Senra ${ }^{1,2}$, Silvia \\ Busquets $^{5}$, Douglas A. Velásquez $z^{1,2}$, Omar Al-Massadi ${ }^{2,6}$, Luis Varela ${ }^{1,2}$, Marina Gándara ${ }^{7}$, \\ Francisco-Javier López-Soriano ${ }^{5}$, Rosalía Gallego ${ }^{7}$, Luisa M. Seoane ${ }^{2,6}$, Josep M. \\ Argiles $^{5}$, Miguel López ${ }^{1,2}$, Roger J. Davis ${ }^{8}$, Guadalupe Sabio ${ }^{9}$, Françoise Rohner- \\ Jeanrenaud ${ }^{4}$, Kamal Rahmouni ${ }^{3}$, Carlos Dieguez ${ }^{1,2}$, and Ruben Nogueiras ${ }^{1,2}$ \\ ${ }^{1}$ Department of Physiology, School of Medicine, University of Santiago de Compostela-Instituto \\ de Investigación Sanitaria, S. Francisco s/n, Santiago de Compostela (A Coruña), Spain ${ }^{2}$ Centro \\ de Investigación Biomédica en Red (CIBER) Fisiopatología de la Obesidad y Nutrición, Santiago \\ de Compostela, Spain ${ }^{3}$ Department of Pharmacology, University of lowa Carver College of \\ Medicine, lowa City, lowa ${ }^{4}$ Laboratory of Metabolism, Division of Endocrinology, Diabetology and \\ Nutrition, Department of Internal Medicine, Faculty of Medicine, University of Geneva, Geneva, \\ Switzerland ${ }^{5}$ Department of Biochemistry and Molecular Biology, University of Barcelona, \\ Barcelona, Spain ${ }^{6}$ Grupo Fisiopatología Endocrina, Complejo Hospitalario Universitario de \\ Santiago-Instituto de Investigación Sanitaria (IDIS/SERGAS) Santiago de Compostela, Spain \\ ${ }^{7}$ Department of Physiology, School of Medicine, University of Santiago de Compostela-Instituto \\ de Investigación Sanitaria, S. Francisco s/n, Santiago de Compostela (A Coruña), Spain ${ }^{8}$ Howard \\ Hughes Medical Institute, Program in Molecular Medicine, University of Massachusetts Medical \\ School, Worcester, Massachusetts ${ }^{9}$ Department of Vascular Biology and Inflammation, Centro \\ Nacional de Investigaciones Cardiovasculares Carlos III, Madrid, Spain
}

\section{Abstract}

BACKGROUND \& AIMS-Specific neuronal circuits modulate autonomic outflow to liver and white adipose tissue. Melanin-concentrating hormone (MCH)-deficient mice are hypophagic, lean, and do not develop hepatosteatosis when fed a high-fat diet. Herein, we sought to investigate the role of $\mathrm{MCH}$, an orexigenic neuropeptide specifically expressed in the lateral hypothalamic area, on hepatic and adipocyte metabolism.

METHODS-Chronic central administration of MCH and adenoviral vectors increasing $\mathrm{MCH}$ signaling were performed in rats and mice. Vagal denervation was performed to assess its effect

\footnotetext{
(C) 2013 by the AGA Institute

Reprint requestsAddress requests for reprints to: Carlos Dieguez, MD, PhD, and Ruben Nogueiras, PhD, Department of Physiology, CIMUS, Avda de Barcelona s/n, 15782 Santiago de Compostela (A Coruña), Spain. carlos.dieguez@usc.es and ruben.nogueiras@usc.es; fax: (34) 881815403.

* Authors share co-first authorship.

Supplementary Material

Note: To access the supplementary material accompanying this article, visit the online version ofGastroenterologyt www.gastrojournal.org, and at http://dx.doi.org/10.1063/j.gastro.2012.10.051.

Conflicts of interest

The authors disclose no conflicts.
} 
on liver metabolism. The peripheral effects on lipid metabolism were assessed by real-time polymerase chain reaction and Western blot.

RESULTS-We showed that the activation of MCH receptors promotes nonalcoholic fatty liver disease through the parasympathetic nervous system, whereas it increases fat deposition in white adipose tissue via the suppression of sympathetic traffic. These metabolic actions are independent of parallel changes in food intake and energy expenditure. In the liver, $\mathrm{MCH}$ triggers lipid accumulation and lipid uptake, with c-Jun N-terminal kinase being an essential player, whereas in adipocytes MCH induces metabolic pathways that promote lipid storage and decreases lipid mobilization. Genetic activation of MCH receptors or infusion of MCH specifically in the lateral hypothalamic area modulated hepatic lipid metabolism, whereas the specific activation of this receptor in the arcuate nucleus affected adipocyte metabolism.

CONCLUSIONS-Our findings show that central MCH directly controls hepatic and adipocyte metabolism through different pathways.

\section{Keywords}

MCH; Liver; Lipid Metabolism; White Adipose Tissue

Melanin-concentrating hormone ( $\mathrm{MCH})$ is a 19-aa neuropeptide selectively expressed in the lateral hypothalamic area (LHA) ${ }^{1}$ with important effects on energy balance. ${ }^{2}$ Central injections of $\mathrm{MCH}$ induce feeding in rodents, and its gene expression is increased after fasting and leptin deficiency. ${ }^{2} \mathrm{MCH}$-induced food intake can be abolished by the coadministration of $\alpha$-melanocyte stimulating hormone, ${ }^{3,4}$ glucagon-like peptide, ${ }^{4}$ and antagonists of the neuropeptide $\mathrm{Y} 1$ receptor. ${ }^{5}$

MCH knockout mice are hypophagic and lean when fed a normal diet, ${ }^{4}$ resistant to agingassociated insulin resistance, ${ }^{6}$ resistant to diet-induced obesity, ${ }^{7}$ and do not develop hepatosteatosis when fed with fat-enriched diets. ${ }^{8}$ Mice that overexpress MCH are obese and hyperleptinemic. ${ }^{9}$ Furthermore, the lack of $\mathrm{MCH}$ attenuates leptin deficiency-induced obesity in ob/obmice. ${ }^{10,11}$

Specific central nervous system (CNS) regions modulate autonomic outflow to white adipose tissue (WAT) and liver, controlling peripheral energy homeostasis. ${ }^{12}$ Particularly within the hypothalamus, several nuclei can control hepatic and adipose metabolism. The paraventricular hypothalamic nucleus of the hypothalamus innervates both tissues, with the LHA and the arcuate nucleus of the hypothalamus (ARC) being upstream of the paraventricular hypothalamic nucleus of the hypothalamus in this pathway. Leptin, ${ }^{13}$ insulin, ${ }^{14,15}$ ghrelin, ${ }^{16}$ neuropeptide $\mathrm{Y},{ }^{17}$ melanocortins, ${ }^{18}$ and glucagon-like peptide- ${ }^{19}$ directly control liver and/or WAT metabolism, and most of those signals require an intact sympathetic nervous system (SNS) to exert their functions. At the hypothalamic level, these molecules act primarily on the neurons located in the ARC. However, the functional role and neural pathways of the LHA ${ }^{20,21}$ mediating the CNS control of peripheral metabolism have been poorly studied. Here, we show that central MCH actions on hepatic lipid metabolism are controlled by the parasympathetic nervous system, whereas adipocyte metabolism is mediated by the SNS. Although some extrahypothalamic areas expressing $\mathrm{MCH}$-immunoreactive fibers or MCH receptors (MCH-R) also might be involved in these actions, we describe 2 different hypothalamic areas mediating the central effects of $\mathrm{MCH}$ on peripheral metabolism, namely the ARC, which is essential for the control of WAT metabolism, and the LHA modulating liver metabolism. 


\section{Material and Methods}

\section{Animals and Surgery}

For all experiments, 8- to 10-week-old (250-300 g) male Sprague-Dawley rats were used (see the Supplementary Materials and Methods section).

\section{Energy Expenditure, Locomotor Activity, Respiratory Quotient, and Lipid Use}

These parameters were analyzed using a cage calorimetry system (LabMaster; TSE Systems, Thuringia, Germany) ${ }^{19}$ (see the Supplementary Materials and Methods section).

\section{Quantitative Reverse-Transcription Polymerase Chain Reaction Procedure}

RNA was extracted using TRIzol reagent (Invitrogen, Paisley, UK) according to the manufacturer's instructions and as previously described. ${ }^{19}$ Primer sequences are described in Supplementary Table 1.

\section{Western Blot Analysis}

Western blot was performed as previously described ${ }^{19}$ (see the Supplementary Materials and Methods section).

\section{Immunohistochemistry}

Immunohistochemistry/immunofluorescence approaches were performed to detect MCH-R, Cellular FBJ osteosarcoma oncogene, phospho-extracellular-signal-regulated kinase, and green fluorescence protein (see the Supplementary Materials and Methods section).

\section{Tissue Triglycerides and Free Fatty Acid Content in WAT, Liver, and Feces}

The extraction procedure for tissue triglycerides (TG) and free fatty acids (FFA) was adapted from methods described previously ${ }^{19}$ (see the Supplementary Materials and Methods section).

\section{Sympathetic Nerve Activity Recording}

Sympathetic nerve activity (SNA) recording was performed as previously described ${ }^{18}$ (see the Supplementary Materials and Methods section).

\section{Enzymatic Activity Assays}

Fatty acid synthase (FAS) and lipoprotein lipase (LPL) activities were measured as previously described ${ }^{18}$ (see the Supplementary Materials and Methods section).

\section{Lipolysis In Vivo}

Lipolysis was assessed as previously reported ${ }^{22}$ (see the Supplementary Materials and Methods section).

\section{Levels of Serum Metabolites and Hormones}

Serum glucose and TG levels (Glucose and Triglyceride Spinreact, Girona, Spain), and FFA levels (Wako, Richmond, VA) were assessed using a commercial kit based on a colorimetric method. Serum insulin levels were measured by radioimmunoassay and serum corticosterone levels were measured using a corticosterone enzyme-linked immunosorbent assay kit (Enzo Life Sciences, Farmingdale, NY) following the manufacturer's instructions. 


\section{Oil Red Staining}

Frozen sections of the livers $(8 \mu \mathrm{m})$ were cut and stained in filtered Oil Red $\mathrm{O}$ for 10 minutes. Sections were washed in distilled water and counterstained with Mayers hematoxylin for 3 minutes. Sections were mounted in aqueous mountant (glycerin jelly).

\section{Stereotaxic Microinjection of Adenoviral Expression Vectors}

Sprague-Dawley rats were placed in a stereotaxic frame and adenoviral vectors overexpressing MCH-R were injected (see the Supplementary Materials and Methods section).

\section{Statistics}

Results are shown as mean \pm standard error of the mean. Statistical analysis was performed using 1-way analysis of variance followed by a post hoc multiple comparison test (Bonferroni test). A Pvalue less than .05 was considered statistically significant.

\section{Results}

\section{The CNS-MCH System Controls Adiposity Independent of Food Intake}

Central infusion of MCH increased food intake in ad libitum-fed rats (MCH-ad lib) (Figure $1 \mathrm{~A}$. A second control group of intracerebroventricular (ICV) MCH-infused animals was pair-fed to match the intake of saline-infused controls (MCH-pf). Weight gain (Figure $1 \mathrm{~B}$, metabolic efficiency (Figure $1 \mathrm{~g}$, and fat mass gain (Figure $1 \mathrm{D}$ ) of ICV MCH-ad lib and $\mathrm{MCH}-p f$ rats was significantly higher than that of controls. Non-fat mass was increased significantly after central infusion of MCH only in rats fed ad libitum (Figure $1 \mathrm{E}$. We did not find any alteration in total energy expenditure or spontaneous locomotor activity (Supplementary Figure 1 A-B.). The expression of uncoupling protein-1, peroxisome proliferator-activated receptor $\gamma$ co-activator-1- $\alpha$, and peroxisome proliferator-activated $\alpha$ receptor remained unchanged in the brown adipose tissue after central MCH treatment (Supplementary Figure 2). However, central administration of MCH significantly increased the respiratory quotient (RQ) (Figure 1 Fand Supplemental Figure 1 Fand Q. Chronic central MCH administration did not change serum levels of glucose, insulin, TG, or cholesterol, but decreased levels of FFAs and corticosterone (Supplementary Table 2).

\section{Central MCH Infusion Controls WAT Lipid Metabolism}

The weight of specific fat depots was increased in MCH-treated groups (Figure $2 \mathrm{~A}$ ). Isoproterenol-stimulated lipolysis markedly increased FFA concentrations in serum in both vehicle and MCH-treated rats (Figure $2 \mathrm{~B}$. However, after 30 and 60 minutes of isoproterenol injection, the levels of FFA in MCH-ad lib and MCH-pf rats were lower than in control rats (Figure $2 \mathrm{~B}$, suggesting that CNS MCH reduces the lipolytic rate. The size of the adipocytes seemed slightly increased in ICV MCH-treated rats in comparison with controls (Figure $2 \mathrm{O}$. Independently of hyperphagia, ICV MCH markedly augmented the gene expression of key enzymes involved in lipid metabolism including acetyl-CoA carboxylase $\alpha$ (ACC $\alpha$ ), FAS, and LPL (Supplementary Figure 3). At the posttranscriptional level, ACC $\alpha$ levels were increased significantly after central infusion of MCH independently of food intake (Figure $2 \mathrm{E}$ ), whereas FAS protein levels and enzymatic activity were higher only in ICV MCH-ad lib-treated rats (Figure 2 Dand E), with no changes in LPL, carnitine palmitoytransferase 1, uncoupling protein-1, or peroxisome proliferator-activated receptor $\mathrm{y}$ co-activator-1- $\alpha$ (Figure $2 \mathrm{E}$ ). Phospho hormone-sensitive lipase (pHSL) and the ratio of pHSL/HSL was decreased in the WAT of MCH-treated rats (Figure $2 \mathrm{E}$. Because the observed changes in the protein levels of enzymes promoting lipid storage cannot entirely explain the food intake-independent increase in fat mass induced by 
CNS MCH, we investigated an alternative mechanism. We found that cell death-inducing DNA fragmentation factor alpha-like effector A (CIDEA) protein levels were increased after CNS-MCH stimulation, indicating a lower lipid oxidation (Figure $2 \mathrm{H} .{ }^{23}$ CIDEA expression is regulated negatively via the mitogen-activated protein kinase c-Jun $\mathrm{NH}(2)$-terminal kinase 1 (JNK1). ${ }^{23}$ Although total JNK1 was unchanged, phosphorylated JNK1 (pJNK1) and the ratio of pJNK1/JNK1 was decreased (Figure $2 \mathrm{H}$ ).

\section{Central MCH Infusion Controls Hepatic Lipid Metabolism}

Central MCH infusion increased TG content (Figure $3 \mathrm{~A}$ ) and decreased FFA levels (Figure $3 \mathrm{~B}$ ) in the liver and serum in both MCH-ad lib and MCH-pf groups (Supplementary Figure 4). We failed to detect any changes at the transcriptional level (Figure $3 \mathrm{O}$. However, at the protein level, phospho-AMP-activated protein kinase (pAMPK), pACC, and ACC $\alpha$ were decreased, whereas LPL was increased in centrally MCH-infused rats independent of hyperphagia (Figure $3 \mathrm{D}$. Accordingly, the activity of LPL in the liver also was up-regulated in both MCH-ad lib and MCH-pf groups (Figure $3 \mathrm{E}$ ). The expression of other enzymes controlling high-density lipoprotein re-uptake (scavenger receptor class B type 1), the endocytosis of cholesterol-rich low-density lipoprotein, and the hepatic lipoprotein assembly and secretion, remained unchanged after chronic CNS MCH stimulation (Figure $3 \mathrm{O}$. Accordingly, transcription factors modulating scavenger receptor class B type 1 expression (farnesoid X receptor and liver receptor homolog 1) were not affected by MCH (Figure 30 . Hepatic JNK1 is involved in steatosis, ${ }^{24}$ and we found that the hepatic levels of total JNK1 were decreased after CNS MCH activation (Figure $3 \mathrm{H}$ ), whereas phosphorylated JNK1 was increased (Figure $3 \mathrm{H}$ ), leading to an increased ratio of pJNK1/JNK1 (Figure $3 \mathrm{H}$ ).

Next, we assessed if CNS MCH also was affecting the lipid absorption. Although the fecal output was unchanged (Supplementary Figure $5 \mathrm{~A}$ ), the content of TG in the feces of both MCH-ad lib and MCH-pf groups was lower than in the controls (Supplementary Figure 5 B, suggesting that CNS MCH increases lipid absorption.

\section{Peripheral MCH Administration Does Not Affect Either Liver or WAT Lipogenic Program}

To rule out the possibility that centrally infused MCH leaks out of the CNS into the circulation and elicits a response by directly acting at the peripheral level, we chronically administered MCH peripherally. At the same doses as those infused centrally, MCH did not change cumulative food intake (Supplementary Figure 6 A), body weight gain (Supplementary Figure 6 B), WAT gene expression (Supplementary Figure 6 9, WAT protein levels (Supplementary Figure 6 Dand E), or hepatic protein levels (Supplementary Figure 6 Fand Q. After subcutaneous infusion it is unlikely that MCH is $100 \%$ absorbed in the plasma. Therefore, we performed a chronic intravenous infusion study with the same amount, volume, and rate of infusion of MCH used for the ICV experiment. These results indicated that chronic intravenous infusion of $\mathrm{MCH}$ increased food intake (Supplementary Figure 7 A) and body weight gain (Supplementary Figure 7 B) when rats were fed ad libitum. However, chronic intravenous infusion of MCH failed to affect adipocyte (Supplementary Figure 7 O or hepatic metabolism (Supplementary Figure 7 D).

\section{Role of the SNS in the Central MCH Control of Adipose Fatty Acid Metabolism}

White adipocytes are connected with the CNS via the autonomic nervous system, in particular the SNS. ${ }^{12} \beta$-adrenergic receptors ( $\beta$-ARs) represent a key link involved in the regulation of adipocyte lipid metabolism by the SNS. ${ }^{12}$ We found that central MCH infusion diminished the expression of the 3 receptors, the decrease in $\beta 3-\mathrm{AR}$ was independent of changes in food intake (Figure $4 \mathrm{~A}$ ). 
To determine whether CNS action of MCH can modulate the efferent SNS subserving WAT, we used multifiber recording to test the effect of CNS MCH activation on WAT SNA. ICV injection of MCH decreased SNA recorded from nerve endings in epididymal WAT (Figure 4 Band Supplementary Figure 8 A). ICV MCH-induced decrease in WAT SNA is dose-dependent (Supplementary Figure $8 \mathrm{~B}$ ). Transection of the WAT nerve distal to the recording site (assessing efferent SNA) did not affect the WAT sympathetic response evoked by ICV MCH (Supplementary Figure 8 g. In contrast, ICV MCH had no significant effect on the afferent nerve activity, recorded after cutting the nerve proximal to the recording site (Supplementary Figure 80 ).

Next, we treated triple ( $\beta 1-\mathrm{AR}, \beta 2-\mathrm{AR}$, and $\beta 3$-AR) adrenoceptor-deficient mice (TKO) with ICV MCH. MCH stimulated cumulative food intake and body weight gain (Figure $4 \mathrm{O}$ in wild-type (WT) mice, whereas TKO mice showed increased food intake, but body weight gain did not increase significantly (Figure $4 \mathrm{O}$. Protein levels of ACC $\alpha$ and FAS were increased significantly in the WAT of WT mice (Figure 4 D, but they remained unchanged in the WAT of TKO mice infused with MCH (Figure 4 E. Finally, hepatic TG content was increased significantly in both WT and TKO mice infused with MCH (Figure 4 H).

\section{Role of the Vagus Nerve in the Central MCH Control of Hepatic Lipid Metabolism}

We sought to determine whether the effect of central MCH on hepatic lipid metabolism involved vagal innervation. The ICV MCH infusion was performed before the dissections of dorsal and ventral branches of the vagus nerve. The effectiveness of this approach was validated by assessing the expected morphologic changes in the stomach (Supplementary Figure 9 A). Central MCH infusion significantly increased cumulative food intake (Supplementary Figure 9 B) and body weight gain (Supplementary Figure $9 \mathrm{O}$ in shamoperated rats, but not in vagotomized (VGX) rats. Stimulation of the CNS MCH system enhanced the hepatic TG content (Figure 5 A), and decreased serum FFA (Figure 5 B) and hepatic FFA (Figure $5 \mathrm{O}$ in sham-operated rats, but failed to do so in VGX rats. Staining of lipid droplets was increased in sham MCH-treated rats, but not in VGX MCH-treated animals (Figure 5 D. The effects of MCH on hepatic pACC and LPL were blunted after vagotomy (Figure $5 \mathrm{E}$ ). Similarly, the increased ratio of pJNK1/JNK1 in the liver of shamoperated rats also was prevented by vagotomy (Figure $5 \mathrm{E}$. In keeping with LPL protein levels, hepatic LPL activity was increased by MCH in SHAM, but not in VGX, rats (Figure $5 \mathrm{H}$. However, vagotomy did not blunt the effects of MCH on the protein levels studied in WAT (Supplementary Figure 9 D).

\section{Role of JNK on Central MCH Control of Peripheral Lipid Metabolism}

MCH administration significantly stimulated food intake in both WT and JNK1-deficient mice (Figure $6 \mathrm{~A}$ ). However, chronic central infusion of $\mathrm{MCH}$ failed to increase body weight in JNK1 knockout (KO) mice (Figure 6 B). Interestingly, CNS infusion of MCH decreased serum levels of FFA in WT mice, but not in JNK1 KO mice (Figure $6 \mathrm{O}$. Central infusion of $\mathrm{MCH}$ increased the protein levels of CIDEA in the WAT of JNK1 KO mice (Supplementary Figure 10 A). In JNK1 KO mice central activation of MCH decreased the hepatic protein levels of pAMPK and pACC, but failed to affect LPL (Figure 6 D).

We also blocked JNK pharmacologically by using the JNK inhibitor SP600125. ${ }^{25}$ When rats were injected twice daily intraperitoneally with $0.5 \mathrm{mg}$ SP600125 during 1 week the orexigenic effect of MCH (Supplementary Figure $10 \mathrm{~B}$ ) and the MCH-induced body weight gain (Supplementary Figure $10 \mathrm{O}$ were abolished. The reduction of serum FFA levels caused by MCH also was reversed by SP600125 (Figure 6 E). The pharmacologic blockade of JNK decreased MCH-induced protein levels of CIDEA in WAT (Supplementary Figure $10 \mathrm{D}$. In the liver, the up-regulation of LPL in MCH-treated rats also was blunted by the 
JNK inhibitor (Figure $6 \mathrm{H}$, whereas the protein levels of pAMPK, AMPKa1, and AMPKa2 were not affected by SP600125 (Figure 6 H).

\section{MCH-R in the ARC and LHA Modulate Adipocyte and Hepatic Lipid Metabolism, Respectively}

The specific activation of MCH-R in the ARC (Figure 7 A) during 1 week increased body weight gain and food intake (Figure $7 \mathrm{~B}$. The adenoviral vectors overexpressing MCH-R increased weight gain and food intake for 6 days (Supplementary Figure 11 Aand B) and the rate of success to reach the ARC was 62.5\% (Supplementary Figure $12 \mathrm{~A}$ ). In rats in which the ARC was not reached there were no differences in food intake or body weight (Supplementary Figure 13 Aand B. MCH-R was co-localized with pERK in the ARC (Supplementary Figure $14 \mathrm{~A}$ ). The levels of C-FOS were up-regulated in the ARC of rats injected with the adenoviral vector overexpressing MCH-R (Supplementary Figure $14 \mathrm{O}$. When we analyzed protein levels in the liver, we found that the activation of MCH-R in the ARC only increased pACC levels in the liver, with no changes in any of the other studied proteins (Figure $7 \mathrm{~g}$. However, in WAT we found a significant increase of ACCa and FAS and a decrease in pHSL and the pJNK/JNK ratio (Supplementary Figure 12 B). To corroborate the results obtained with adenoviruses, we next used osmotic mini-pumps connected to the ARC. We found that chronic infusion (1 week) of MCH directly into the ARC increased body weight and food intake (Figure $7 \mathrm{~B}$ ). The analysis of protein levels in the liver failed to show any changes in any of the studied proteins (Figure $7 \mathrm{O}$. However, after the infusion of MCH into the ARC we found increased levels of ACCa, CIDEA, and FAS, and decreased levels of pJNK/JNK and pHSL in the WAT (Supplementary Figure $12 \mathrm{~B}$.

Next, we assessed the effects of the specific activation of MCH-R in the LHA (Figure 7 D. We found a significant increase in body weight gain and food intake (Figure $7 \mathrm{E}$. The adenoviral vectors overexpressing MCH-R increased weight gain and food intake for 6 days (Supplementary Figure 11 Cand D) and the rate of success to reach the LHA was 87.5\% (Supplementary Figure $12 \mathrm{~A}$ ). In rats in which the LHA was not reached there were no differences in food intake or body weight (Supplementary Figure 13 Cand D. MCH-R also was co-localized with pERK in the LHA (Supplementary Figure $14 \mathrm{~B}$. The levels of c-Fos were up-regulated in the LHA of rats injected with the adenoviral vector overexpressing MCH-R (Supplementary Figure $14 \mathrm{O}$. At the hepatic level, there was a down-regulation of pACC, whereas LPL and the ratio of pJNK/JNK were augmented significantly (Figure $7 \mathrm{H}$ ). In contrast, in WAT all the studied proteins remained unaltered after the activation of MCH$\mathrm{R}$ in the LHA (Supplementary Figure $12 \mathrm{O}$. To corroborate these results, we used osmotic minipumps connected to the LHA. We found that chronic infusion (1 week) of MCH directly into the LHA did not affect body weight or food intake (Figure $7 \mathrm{E}$ ). In the liver of rats treated with MCH into the LHA we also found a decrease in pACC, and an increase in LPL and pJNK/JNK levels (Figure $7 \mathrm{H}$ ), although we failed to detect any significant change in the levels of the studied proteins in WAT (Supplementary Figure $12 \mathrm{O}$.

Finally, we investigated the potential role of the ventromedial hypothalamic nucleus of the hypothalamus (VMH) mediating the central actions of $\mathrm{MCH}$ on energy balance (Supplementary Figure 15 A). However, the specific activation of MCH-R in this nucleus did not modify body weight gain, food intake, or protein levels in liver or WAT (Supplementary Figure 15 B-B.).

\section{Discussion}

We report here that the central MCH system directly controls peripheral lipid metabolism. Specifically, we show that central infusion of MCH stimulates lipid absorption and lipid 
deposition in WAT and liver independently of its orexigenic action or changes in energy expenditure. Our results suggest a molecular basis for a CNS MCH-induced switch in nutrient partitioning and substrate use. Those actions likely occur through effects on 2 different pathways: the SNS mediates the effects of CNS MCH on adipocyte metabolism, whereas the parasympathetic vagus nerve controls the effects of CNS MCH on hepatic metabolism. Also, we show that both effects show a nucleus-specific pattern within the hypothalamus. Thus, the specific activation of MCH-R in the ARC modulates adipocyte metabolism, whereas when we triggered MCH-R in the LHA, marked changes were found in hepatic metabolism.

Pharmacologic or genetic manipulation of MCH causes important alterations in feeding behavior, body weight, and insulin resistance. ${ }^{2,4,6,9,10,26,27}$ In the current work, we confirmed that chronic central infusion of MCH increases food intake and body weight gain, and also stimulates lipid absorption and lipid deposition in WAT and liver. Interestingly, those changes not only were independent of feeding behavior, but also of energy expenditure, as shown in our indirect calorimetry data. The increased respiratory quotient and the measured levels of lipogenic genes and proteins suggest that central MCH favors lipid storage through changes in nutrient partitioning and substrate use. The increased WAT and hepatic lipid deposition were mediated by tissue-specific molecular mechanisms.

MCH-treated rats had increased hepatic TG storage along with down-regulation of pAMPK and PACC and specific up-regulation of hepatic activity of JNK1 and LPL. Pharmacologic ${ }^{28,29}$ and genetic ${ }^{30-32}$ inhibition of JNK1 improves high-fat diet-induced insulin resistance and inflammatory changes. Consistent with this, and in agreement with our findings after CNS MCH stimulation, JNK activity was reported to be increased abnormally in obesity. ${ }^{30}$ It is also important to point out that even though LPL is expressed at low levels in the liver in normal conditions, it is increased markedly in morbidly obese patients with nonalcoholic fatty liver disease. ${ }^{33}$ Our observations suggest that central MCH stimulates hepatic TG storage and uptake. The parasympathetic vagus nerve appears to be a crucial communication link mediating CNS control of hepatic metabolism. ${ }^{34,35} \mathrm{We}$ therefore tested the hypothesis that the vagus nerve may be responsible for mediating central $\mathrm{MCH}$ actions on liver metabolism. When we investigated the specific effects of surgical total vagotomy on hepatic lipid metabolism, the hepatic TG and FFA content in MCHtreated VGX rats remained unchanged. The molecular targets mediating TG and FFA content in the liver appear to be JNK1 and LPL because the up-regulation of these key molecules modulating fatty acid metabolism after central MCH infusion in control rats was blunted in MCH-treated VGX rats. These data show that the vagus nerve is mediating the CNS MCH-induced regulation of hepatic lipid metabolism. To further evaluate the relevance of JNK1 in the actions of the CNS-MCH system, we centrally infused MCH in JNK1-deficient mice. We found that MCH failed to decrease serum FFA in mice lacking JNK1, and this could be explained by the inability of MCH to up-regulate LPL in JNK1 KO mice. In fact, it has been shown that a lack of JNK1 could affect the expression of LPL induced by high-fat diet. ${ }^{36}$ Consistent with data obtained in genetically manipulated mice, the pharmacologic blockade of JNK also blunted the CNS MCH-mediated actions on food intake, body weight, serum FFA, and hepatic LPL protein levels. Therefore, JNK1 seems to be an essential player in the modulation of central MCH actions on hepatic TG uptake, even though it also is plausible to hypothesize that other isoforms of JNK might play a role in the control of hepatic metabolism. Thus, 2 different mechanisms appear to modulate hepatic lipid storage. On one hand, decreased levels of pAMPK are related to increased de novo lipogenesis. On the other hand, the specific stimulation of JNK1 activity and LPL levels indicate that the CNS-MCH stimulation triggers hepatic lipid uptake. 
The SNS connects WAT via a neuronal circuit with homeostatic control areas within the hypothalamus and other brain areas. ${ }^{12,37}$ Combining electrophysiological studies and genetically manipulated mice lacking $\beta$-ARs, we showed that central infusion of $\mathrm{MCH}$ decreases the expression of $\beta$-ARs and the efferent SNA subserving in WAT. Consistently, CNS-MCH stimulation failed to change body weight and WAT protein levels of lipogenic enzymes in TKO mice, indicating that an intact SNS is necessary for central MCH actions on body weight to occur. Within the WAT, this action seems to be modulated by 2 processes. First, CNS-MCH stimulation triggers lipid accumulation in WAT through an upregulation of ACCa and FAS. However, this action partially is dependent on the orexigenic role of $\mathrm{MCH}$ because FAS protein levels and activity were increased only in $\mathrm{MCH}$-ad lib rats. Those data suggested the involvement of a second pathway controlling the CNS MCHinduced fat storage. We found that CIDEA, an enzyme strongly linked to the regulation of fatty acid metabolism, ${ }^{38}$ was increased in the WAT after central ICV-MCH infusion. According to previous studies in adipocytes, ${ }^{23}$ the activation of JNK1, a kinase that controls cell development and function by regulation of transcription, ${ }^{39}$ blocks CIDEA. Thus, the increased levels of CIDEA in WAT after CNS-MCH stimulation suggest a decrease in lipolysis, a result that supports the decreased lipolysis found in $\mathrm{MCH}$-treated rats in comparison with vehicle rats.

We finally investigated the specific sites of action for $\mathrm{MCH}$ within the hypothalamus. Indeed, $\mathrm{MCH}$-ir fibers and MCH-R are distributed widely throughout the $\mathrm{CNS}^{1,40}$ and are not restricted to the hypothalamus. Within the hypothalamus, MCH-R is located in the ARC, $\mathrm{LHA}$, and $\mathrm{VMH},{ }^{40} 3$ important nuclei modulating energy homeostasis. Our results show that activation of MCH-R in both ARC and LHA increases body weight and food intake, whereas the activation of $\mathrm{MCH}-\mathrm{R}$ in the $\mathrm{VMH}$ had no effect. We also infused $\mathrm{MCH}$ directly into the ARC and LHA during 1 week and confirmed that the chronic infusion of $\mathrm{MCH}$ directly into the LHA controls hepatic lipid metabolism, whereas the chronic infusion of $\mathrm{MCH}$ directly into the ARC controls adipocyte lipid metabolism. Overall, these findings indicate that MCH-Rs in the ARC are needed for the control of adipocyte metabolism, whereas MCH-Rs in the LHA are essential for hepatic metabolism. These results are in agreement with previous reports showing that the ARC plays an important role in the control of the SNS ${ }^{41,42}$ whereas the LHA interacts with the vagus nerve. ${ }^{43}$

In summary, we provide a combination of pharmacologic and genetic evidence to show that the central MCH system increases lipid storage via direct modulation of hepatic and adipocyte metabolism (Supplementary Figure 16). Overall, our findings reveal 2 novel circuits linking MCH, a LHA-produced neuropeptide, with peripheral lipid metabolism, and support the crucial concept that specific hypothalamic nuclei have independent autonomic outflow pathways to individual metabolic organs.

\section{Supplementary Material}

Refer to Web version on PubMed Central for supplementary material.

\section{Acknowledgments}

The authors deeply thank Professor Antonio Vidal-Puig and Dr Sergio Rodríguez-Cuenca (University of Cambridge, UK) for kindly revising and critically reading the article.

Funding

Supported by grants from the Ministerio de Educacion y Ciencia (BFU2011 to C.D., RyC-2007-00211 to M.L., RYC-2008-02219 and SAF2009-07049 to R.N.; RYC-2009-04972 and SAF2010-19347 to G.S.), Xunta de Galicia (10PXIB208164PR to M.L., and 2010/14 to R.N.), Fondo Investigationes Sanitarias (PS09/01880 to M.L.); Swiss National Science Foundation, Bern, Switzerland number 31003A-134919/1 (F.R.J.). CIBER de Fisiopatología de la 
Obesidad y Nutrición is an initiative of ISCIII and is supported by the US National Institutes of Health (grant HL084207) and the American Diabetes Association (grant 1-11-BS-127 to K.R.). The research leading to these results also has received funding from the European Community's Seventh Framework Programme under grant agreements (number 245009: “NeuroFAST” to C.D., M.L., and R.N., ERC-2010-StG-OBECAN-260464 to G.S.; and ERC-2011-StG-OBESITY53-281408 to R.N.).

\section{Abbreviations used in this paper}

ACC $₫$

ARC

CIDEA

CNS

FAS

FFA

ICV

JNK1

LHA

LPL

MCH

MCH-ad lib

MCH-pf

MCH-R

PAMPK

pHSL

RQ

SNA

SNS

TG

TKO

VGX

VMH

WAT

WT
acetyl-CoA carboxylase $\alpha$

arcuate nucleus of the hypothalamus

cell death-inducing DNA fragmentation factor alpha-like effector A central nervous system

fatty acid synthase

free fatty acids

intracerebroventricular

c-Jun $\mathrm{NH}(2)$-terminal kinase 1

lateral hypothalamic area

lipoprotein lipase

melanin-concentrating hormone

ad libitum-fed melanin-concentrating hormone

pair fed melanin-concentrating hormone

melanin-concentrating hormone receptor

phospho-AMP-activated protein kinase

phospho hormone sensitive lipase

respiratory quotient

sympathetic nerve activity

sympathetic nervous system

triglycerides

triple adrenoceptor-deficient mice

vagotomized

ventromedial hypothalamic nucleus of the hypothalamus

white adipose tissue

wild type

\section{References}

1. Broberger C, De Lecea L, Sutcliffe JG, et al. Hypocretin/orexin- and melanin-concentrating hormone-expressing cells form distinct populations in the rodent lateral hypothalamus: relationship to the neuropeptide Y and agouti gene-related protein systems. J Comp Neurol. 1998; 402:460-474. [PubMed: 9862321]

2. Qu D, Ludwig DS, Gammeltoft S, et al. A role for melanin-concentrating hormone in the central regulation of feeding behaviour. Nature. 1996; 380:243-247. [PubMed: 8637571] 
3. Grill HJ, Ginsberg AB, Seeley RJ, et al. Brainstem application of melanocortin receptor ligands produces long-lasting effects on feeding and body weight. J Neurosci. 1998; 18:10128-10135. [PubMed: 9822766]

4. Shimada M, Tritos NA, Lowell BB, et al. Mice lacking melaninconcentrating hormone are hypophagic and lean. Nature. 1998; 396:670-674. [PubMed: 9872314]

5. Chaffer CL, Morris MJ. The feeding response to melanin-concentrating hormone is attenuated by antagonism of the NPY Y(1)- receptor in the rat. Endocrinology. 2002; 143:191-197. [PubMed: 11751609]

6. Jeon JY, Bradley RL, Kokkotou EG, et al. MCH-/- mice are resistant to aging-associated increases in body weight and insulin resistance. Diabetes. 2006; 55:428-434. [PubMed: 16443777]

7. Kokkotou E, Jeon JY, Wang X, et al. Mice with MCH ablation resist diet-induced obesity through strain-specific mechanisms. Am J Physiol Regul Integr Comp Physiol. 2005; 289:R117-R124. [PubMed: 15731402]

8. Wang Y, Ziogas DC, Biddinger S, et al. You deserve what you eat: lessons learned from the study of the melanin-concentrating hormone (MCH)-deficient mice. Gut. 2010; 59:1625-1634. [PubMed: 20966023]

9. Ludwig DS, Tritos NA, Mastaitis JW, et al. Melanin-concentrating hormone overexpression in transgenic mice leads to obesity and insulin resistance. J Clin Invest. 2001; 107:379-386. [PubMed: 11160162]

10. Segal-Lieberman G, Bradley RL, Kokkotou E, et al. Melanin-concentrating hormone is a critical mediator of the leptin-deficient phenotype. Proc Natl Acad Sci U S A. 2003; 100:10085-10090. [PubMed: 12897241]

11. Alon T, Friedman JM. Late-onset leanness in mice with targeted ablation of melanin concentrating hormone neurons. J Neurosci. 2006; 26:389-397. [PubMed: 16407534]

12. Bartness TJ, Song CK. Thematic review series: adipocyte biology. Sympathetic and sensory innervation of white adipose tissue. J Lipid Res. 2007; 48:1655-1672. [PubMed: 17460327]

13. Buettner C, Muse ED, Cheng A, et al. Leptin controls adipose tissue lipogenesis via central, STAT3-independent mechanisms. Nat Med. 2008; 14:667-675. [PubMed: 18516053]

14. Koch L, Wunderlich FT, Seibler J, et al. Central insulin action regulates peripheral glucose and fat metabolism in mice. J Clin Invest. 2008; 118:2132-2147. [PubMed: 18451994]

15. Scherer T, O’Hare J, Diggs-Andrews K, et al. Brain insulin controls adipose tissue lipolysis and lipogenesis. Cell Metab. 2011; 13:183-194. [PubMed: 21284985]

16. Theander-Carrillo C, Wiedmer P, Cettour-Rose P, et al. Ghrelin action in the brain controls adipocyte metabolism. J Clin Invest. 2006; 116:1983-1993. [PubMed: 16767221]

17. Zarjevski N, Cusin I, Vettor R, et al. Chronic intracerebroventricular neuropeptide-Y administration to normal rats mimics hormonal and metabolic changes of obesity. Endocrinology. 1993; 133:1753-1758. [PubMed: 8404618]

18. Nogueiras R, Wiedmer P, Perez-Tilve D, et al. The central melanocortin system directly controls peripheral lipid metabolism. J Clin Invest. 2007; 117:3475-3488. [PubMed: 17885689]

19. Nogueiras R, Perez-Tilve D, Veyrat-Durebex C, et al. Direct control of peripheral lipid deposition by CNS GLP-1 receptor signaling is mediated by the sympathetic nervous system and blunted in diet-induced obesity. J Neurosci. 2009; 29:5916-5925. [PubMed: 19420258]

20. Perez CA, Stanley SA, Wysocki RW, et al. Molecular annotation of integrative feeding neural circuits. Cell Metab. 2011; 13:222-232. [PubMed: 21284989]

21. Stanley S, Pinto S, Segal J, et al. Identification of neuronal subpopulations that project from hypothalamus to both liver and adipose tissue polysynaptically. Proc Natl Acad Sci U S A. 2010; 107:7024-7029. [PubMed: 20351287]

22. Mohan P, Bloom S. Lipolysis is an important determinant of isoproterenol-induced myocardial necrosis. Cardiovasc Pathol. 1999; 8:255-261. [PubMed: 10533957]

23. Nordstrom EA, Ryden M, Backlund EC, et al. A human-specific role of cell death-inducing DFFA (DNA fragmentation factor-alpha)-like effector A (CIDEA) in adipocyte lipolysis and obesity. Diabetes. 2005; 54:1726-1734. [PubMed: 15919794]

24. Sabio G, Cavanagh-Kyros J, Ko HJ, et al. Prevention of steatosis by hepatic JNK1. Cell Metab. 2009; 10:491-498. [PubMed: 19945406] 
25. Kluwe J, Pradere JP, Gwak GY, et al. Modulation of hepatic fibrosis by c-Jun-N-terminal kinase inhibition. Gastroenterology. 2010; 138:347-359. [PubMed: 19782079]

26. Della-Zuana O, Presse F, Ortola C, et al. Acute and chronic administration of melaninconcentrating hormone enhances food intake and body weight in Wistar and Sprague-Dawley rats. Int J Obes Relat Metab Disord. 2002; 26:1289-1295. [PubMed: 12355323]

27. Mashiko S, Ishihara A, Gomori A, et al. Antiobesity effect of a melanin-concentrating hormone 1 receptor antagonist in diet-induced obese mice. Endocrinology. 2005; 146:3080-3086. [PubMed: 15817671]

28. Cleasby ME, Dzamko N, Hegarty BD, et al. Metformin prevents the development of acute lipidinduced insulin resistance in the rat through altered hepatic signaling mechanisms. Diabetes. 2004; 53:3258-3266. [PubMed: 15561958]

29. Kaneto H, Nakatani Y, Miyatsuka T, et al. Possible novel therapy for diabetes with cell-permeable JNK-inhibitory peptide. Nat Med. 2004; 10:1128-1132. [PubMed: 15448687]

30. Hirosumi J, Tuncman G, Chang L, et al. A central role for JNK in obesity and insulin resistance. Nature. 2002; 420:333-336. [PubMed: 12447443]

31. Nakatani Y, Kaneto H, Kawamori D, et al. Modulation of the JNK pathway in liver affects insulin resistance status. J Biol Chem. 2004; 279:45803-45809. [PubMed: 15331609]

32. Sabio G, Das M, Mora A, et al. A stress signaling pathway in adipose tissue regulates hepatic insulin resistance. Science. 2008; 322:1539-1543. [PubMed: 19056984]

33. Pardina E, Baena-Fustegueras JA, Llamas R, et al. Lipoprotein lipase expression in livers of morbidly obese patients could be responsible for liver steatosis. Obes Surg. 2009; 19:608-616. [PubMed: 19301078]

34. Kalsbeek A, Bruinstroop E, Yi CX, et al. Hypothalamic control of energy metabolism via the autonomic nervous system. Ann N Y Acad Sci. 2010; 1212:114-129. [PubMed: 21070249]

35. Lam TK, Schwartz GJ, Rossetti L. Hypothalamic sensing of fatty acids. Nat Neurosci. 2005; 8:579-584. [PubMed: 15856066]

36. Sabio G, Kennedy NJ, Cavanagh-Kyros J, et al. Role of muscle c-Jun NH2-terminal kinase 1 in obesity-induced insulin resistance. Mol Cell Biol. 2010; 30:106-115. [PubMed: 19841069]

37. Bartness TJ, Shrestha YB, Vaughan CH, et al. Sensory and sympathetic nervous system control of white adipose tissue lipolysis. Mol Cell Endocrinol. 2010; 318:34-43. [PubMed: 19747957]

38. Zhou Z, Yon Toh S, Chen Z, et al. Cidea-deficient mice have lean phenotype and are resistant to obesity. Nat Genet. 2003; 35:49-56. [PubMed: 12910269]

39. Davis RJ. Signal transduction by the JNK group of MAP kinases. Cell. 2000; 103:239-252. [PubMed: 11057897]

40. Hervieu GJ, Cluderay JE, Harrison D, et al. The distribution of the mRNA and protein products of the melanin-concentrating hormone $(\mathrm{MCH})$ receptor gene, slc- 1 , in the central nervous system of the rat. Eur J Neurosci. 2000; 12:1194-1216. [PubMed: 10762350]

41. Bamshad M, Aoki VT, Adkison MG, et al. Central nervous system origins of the sympathetic nervous system outflow to white adipose tissue. Am J Physiol. 1998; 275:R291-R299. [PubMed: 9688991]

42. Dampney RA. Arcuate nucleus-a gateway for insulin's action on sympathetic activity. J Physiol. 2011; 589:2109-2110. [PubMed: 21532029]

43. Jiang C, Fogel R, Zhang X. Lateral hypothalamus modulates gutsensitive neurons in the dorsal vagal complex. Brain Res. 2003; 980:31-47. [PubMed: 12865157] 

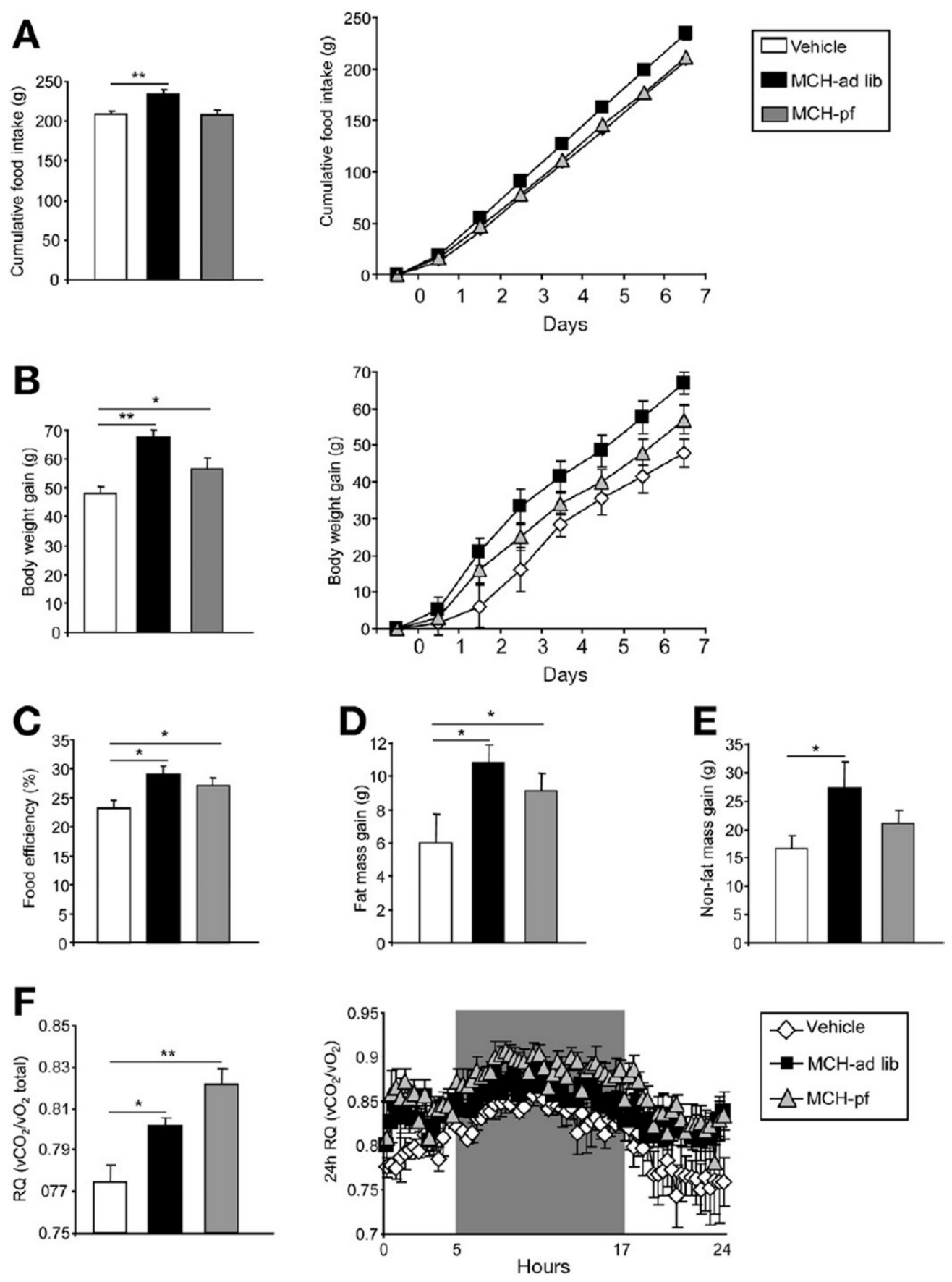

Figure 1.

Effect of a 7-day ICV MCH (10 $\mu \mathrm{g}$ /day) infusion on cumulative ( $\mathrm{A}$ ) food intake, ( B body weight gain, ( $\mathrm{O}$ food efficiency, ( D) fat mass gain, ( E) non-fat mass gain, and ( B RQ.

Values are mean \pm standard error of the mean of $7-8$ animals per group. ${ }^{*} \mathrm{P}<.05$ and $* * \mathrm{P}$ $<.01$ vs controls. 
A

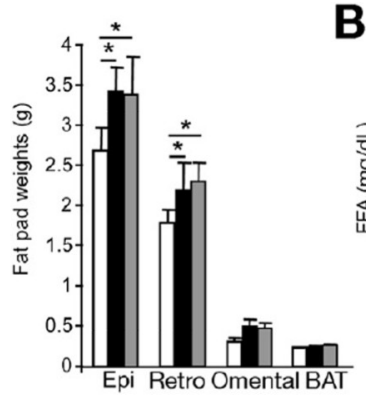

C

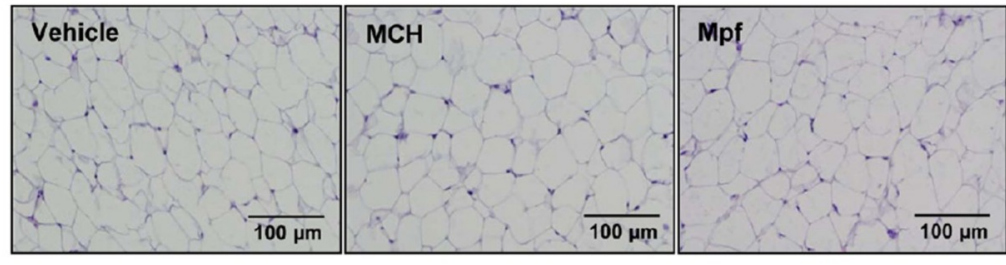

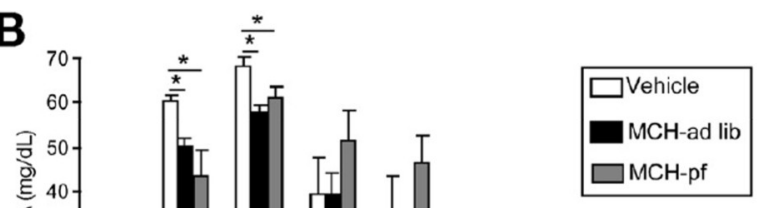

E
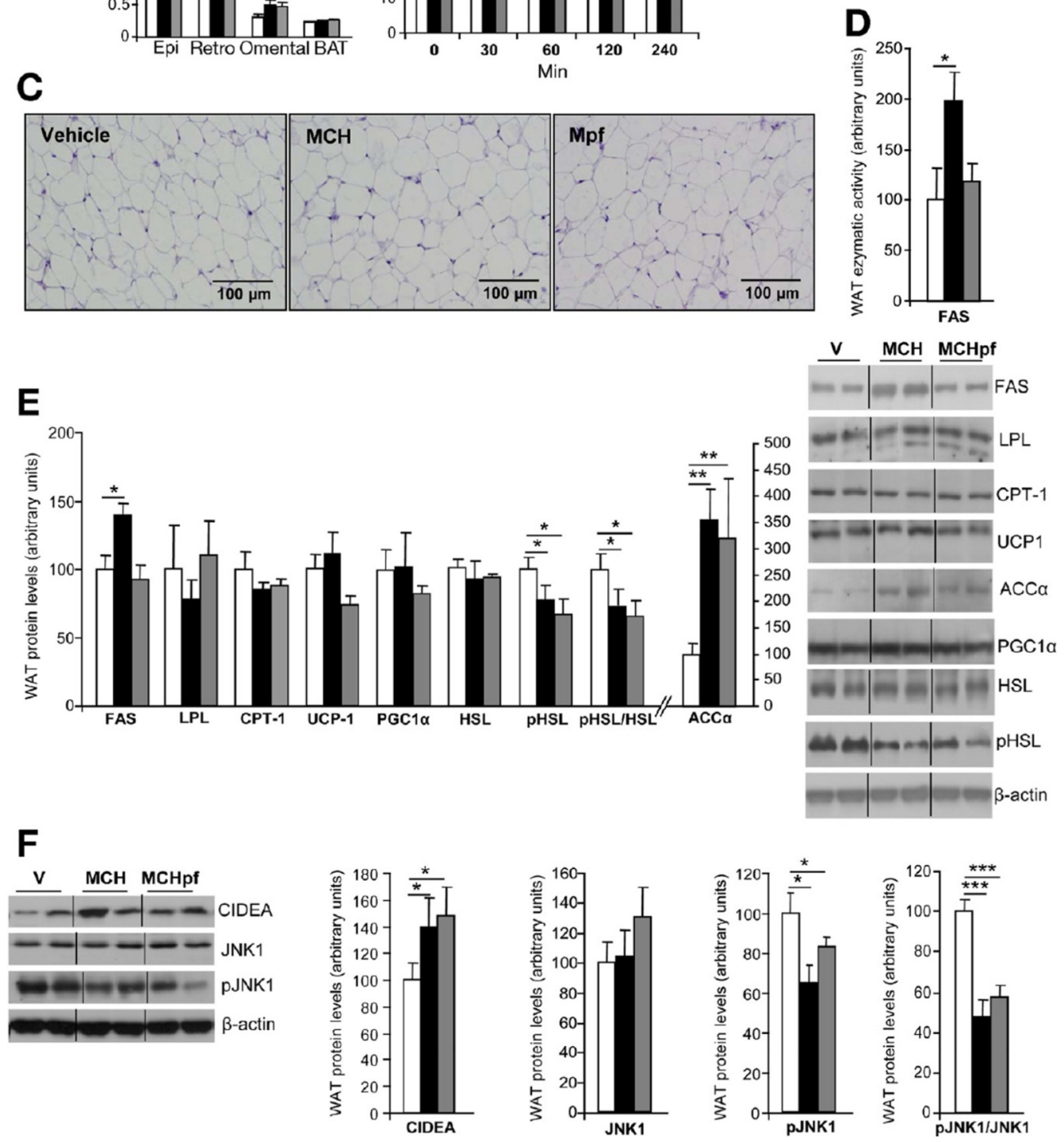

Figure 2.

Effect of a 7-day ICV MCH (10 $\mu \mathrm{g}$ /day) infusion on ( A) different fat pad weights; ( B) isoproterenol-stimulated lipolysis; ( $\mathrm{O}$ histology of WAT; ( D) WAT enzymatic activity of FAS; ( E) epididymal WAT protein levels of FAS, LPL, CPT-1, uncoupling protein-1 (UCP-1), peroxisome proliferator-activated receptor gamma co-activator-1- $\alpha$ (PGC1 $\alpha$ ), HSL, pHSL, and ACCa; and ( H WAT protein levels of CIDEA, JNK1, pJNK1, and the ratio of $\mathrm{pJNK} 1 / \mathrm{JNK} 1$. Protein $\beta$-actin levels were used to normalize protein levels. Values are mean \pm standard error of the mean of $7-8$ animals per group. ${ }^{*} \mathrm{P}<.05,{ }^{* *} \mathrm{P}<.01$; and $* * * \mathrm{P}<.001$ vs controls. 
A

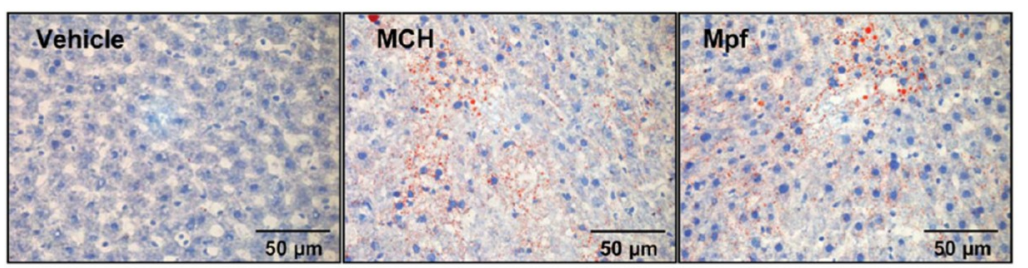

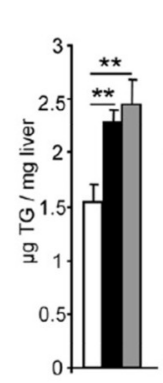

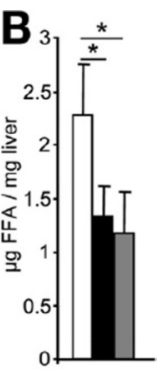

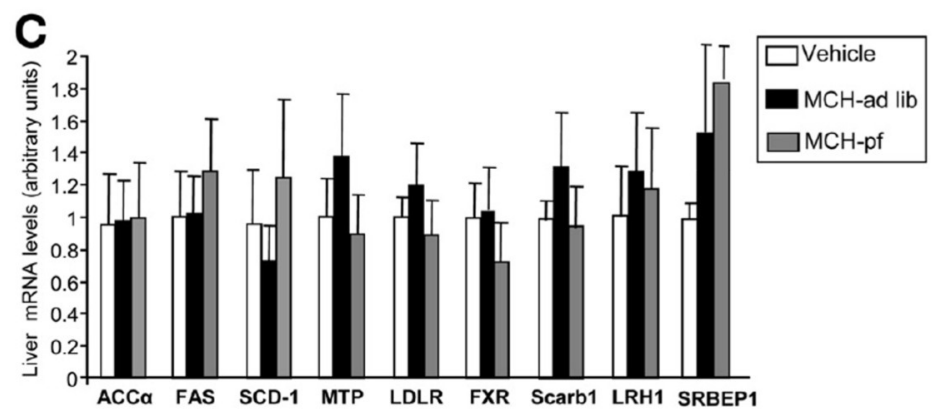

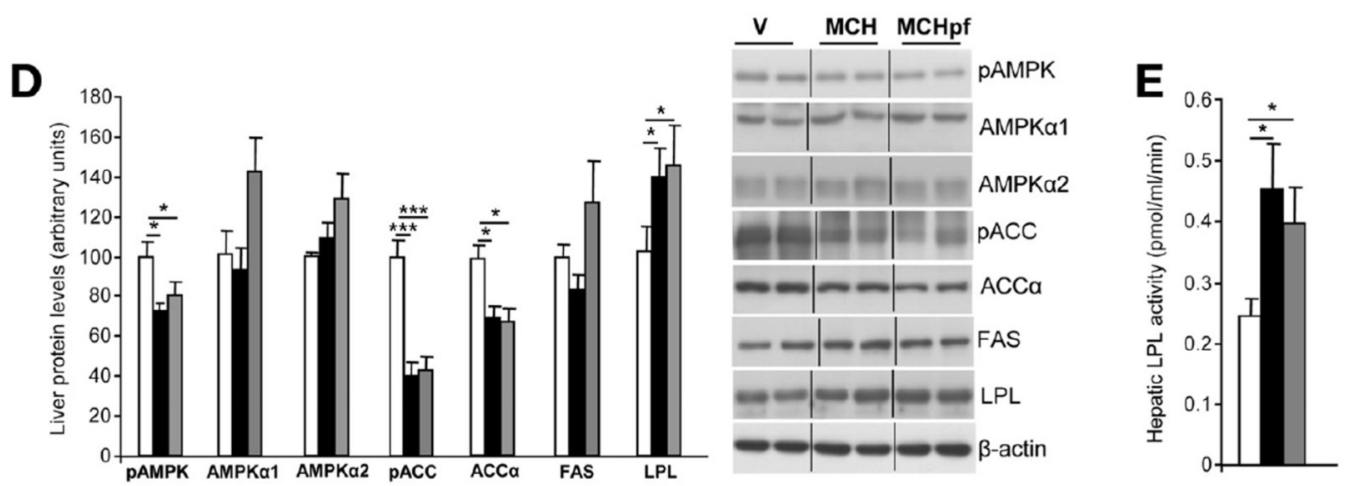

$\mathbf{F}$

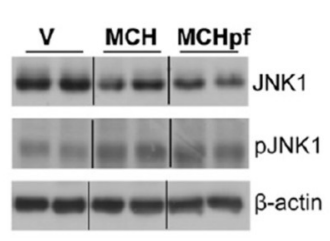

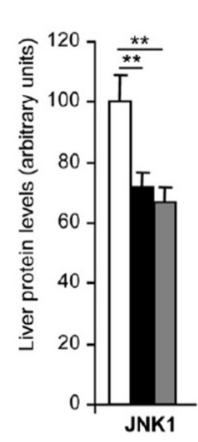
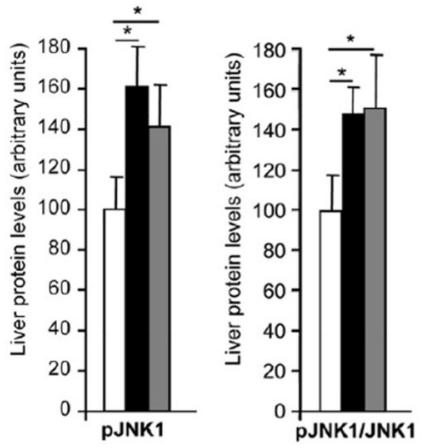

Figure 3.

Effect of a 7-day ICV MCH (10 $\mu \mathrm{g}$ /day) infusion on ( $\mathrm{A})$ hepatic TG content represented by oil red ( left and total TG content ( right; ( B FFA; ( O messenger RNA (mRNA) expression of ACCa, FAS, SCD-1, microsomal TG transfer protein (MTP), low-density lipoprotein receptor (LDLR), farnesoid X receptor (FXR), scavenger receptor class B type 1 (Scarb1), liver receptor homolog 1 (LRH1), and SREBP1; ( D) protein levels of pAMPK, AMPKa1, AMPKa2, pACC, ACCa, FAS, and LPL; ( E) hepatic LPL activity; and ( H protein levels of JNK1, pJNK1, and the ratio of pJNK1/JNK1. Data are presented as values normalized to $18 \mathrm{~S}$, which was used as a housekeeping gene. Protein levels are relative to controls and $\beta$ - 
actin, which was used to normalize protein levels. Values are mean \pm standard error of the mean of $7-8$ animals per group. ${ }^{*} \mathrm{P}<.05,{ }^{* *} \mathrm{P}<.01$, and ${ }^{* * *} \mathrm{P}<.001$ vs controls. 
A

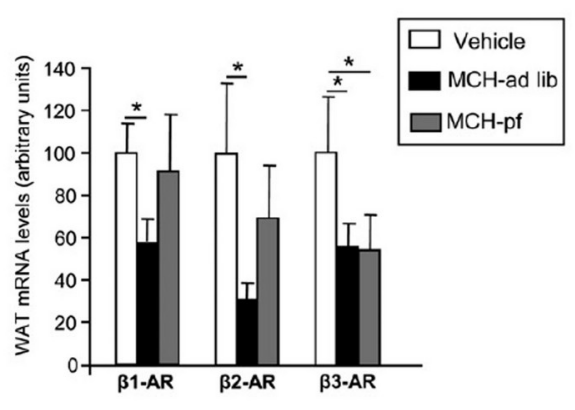

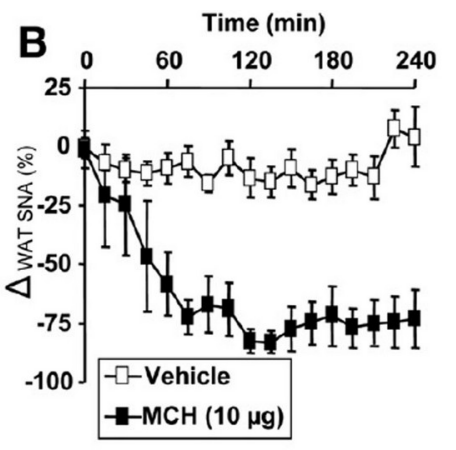

C $\begin{array}{|lr|}\square \text { WT vehicle } & \square \text { TKO vehicle } \\ \text { WT MCH } & \square \text { TKO MCH } \\ \text { T }^{*} & { }^{30} \text { * }\end{array}$
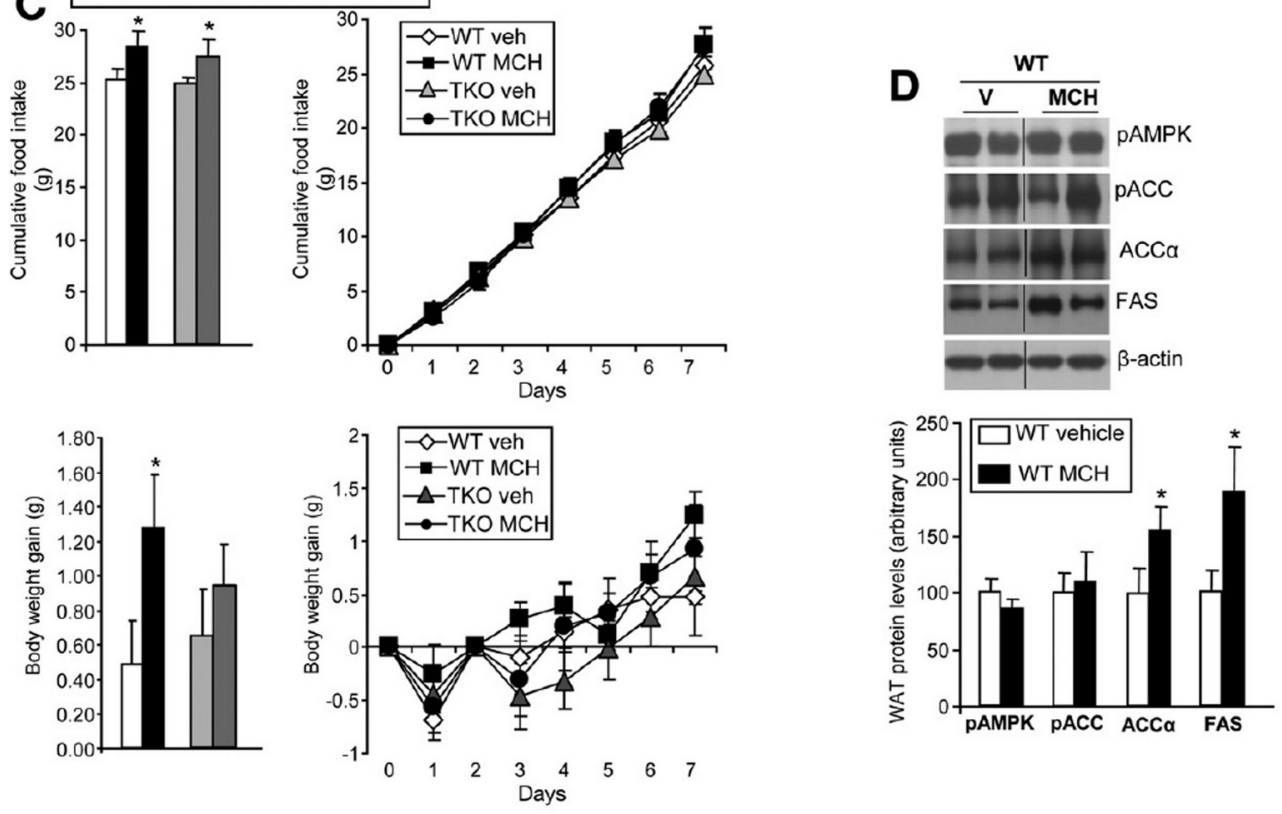

E

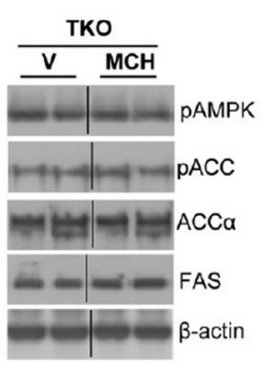

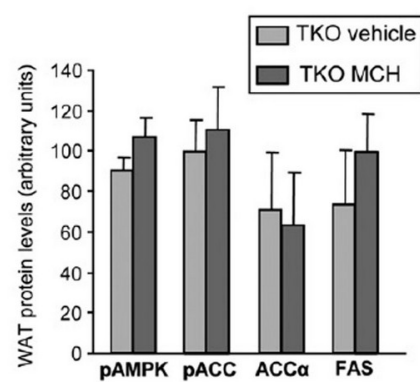

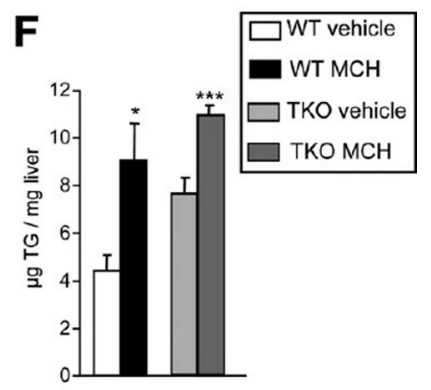

Figure 4.

( A) Effect of a 7-day ICV MCH (10 $\mu \mathrm{g}$ /day) infusion on epididymal WAT messenger RNA (mRNA) expression of $\beta 1-A R, \beta 2-A R$, and $\beta 3-A R$. ( B) Effect of ICV administration of $\mathrm{MCH}$ on SNA subserving epididymal WAT in anesthetized rats. Effect of a 7-day ICV MCH (2.5 $\mu \mathrm{g} /$ day) infusion on ( $\mathrm{O}$ cumulative food intake and body weight gain; ( D WAT protein levels of pAMPK, pACC, ACCa, and FAS in WT; ( E) TKO mice; and ( $)$ hepatic TG content in WT and TKO mice. Values are mean \pm standard error of the mean of 6 animals per group. ${ }^{*} \mathrm{P}<.05$ and $* * * \mathrm{P}<.001$ vs controls. 

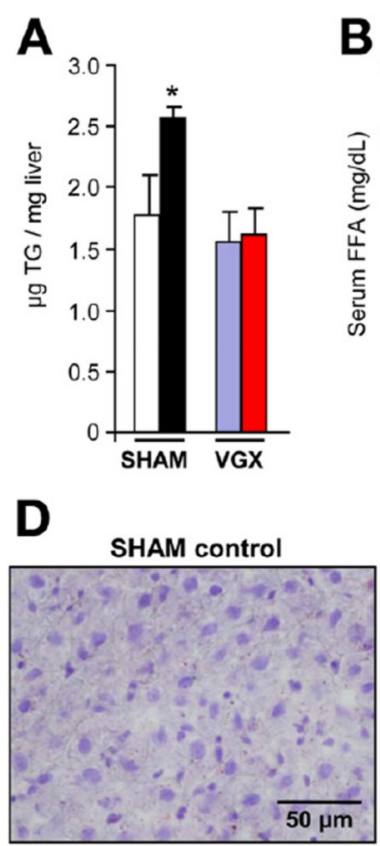

VGX control
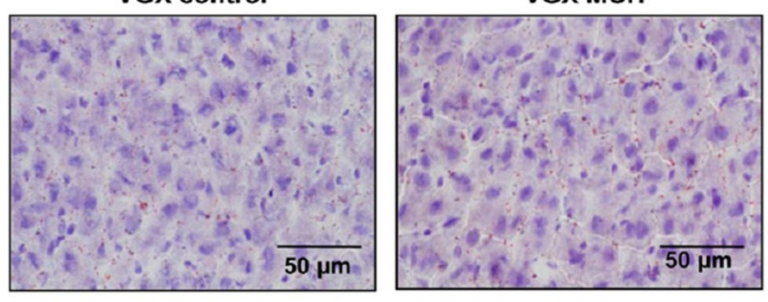

B

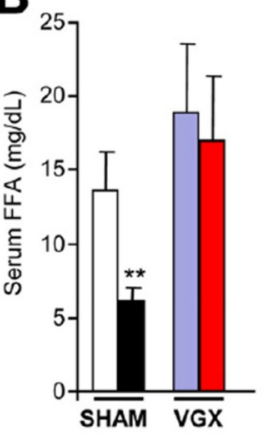

SHAM MCH

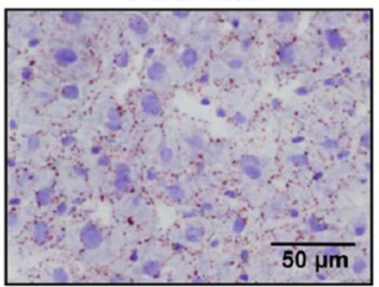

VGX MCH

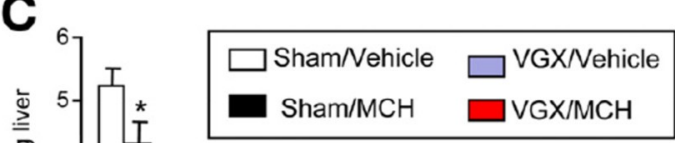

采

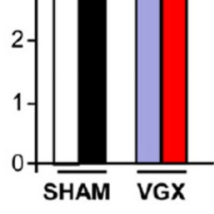

E

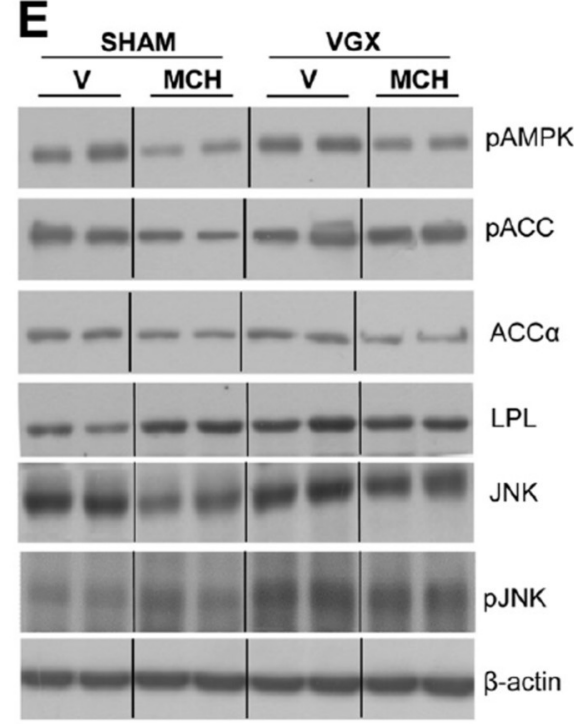

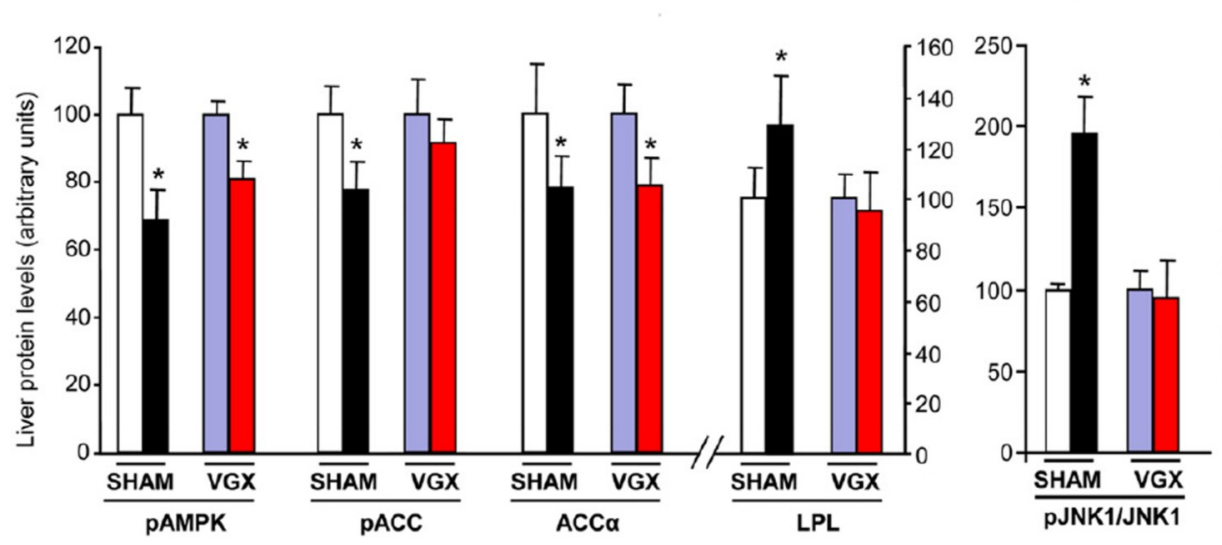

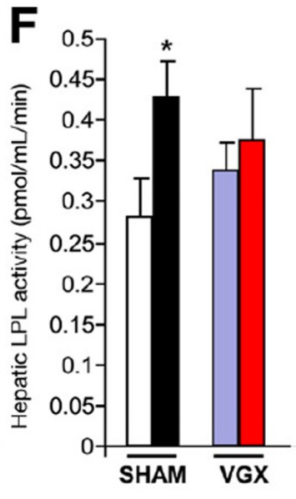

Figure 5.

Effect of a 7-day ICV MCH (10 $\mu \mathrm{g}$ /day) infusion on ( A) hepatic TG content; ( B serum FFA; ( $\mathrm{Q}$ hepatic FFA; ( D) oil red staining; ( $\mathrm{E}$ ) hepatic protein levels of pAMPK, pACC, ACCa, LPL, and the ratio of pJNK1/JNK1; and the ( $\mathrm{B}$ hepatic LPL activity in shamoperated rats and VGX rats. $\beta$-actin was used to normalize protein levels. Values are mean \pm standard error of the mean of $6-8$ animals per group. ${ }^{*} \mathrm{P}<.05$ and ${ }^{* *} \mathrm{P}<.01$ vs controls. 

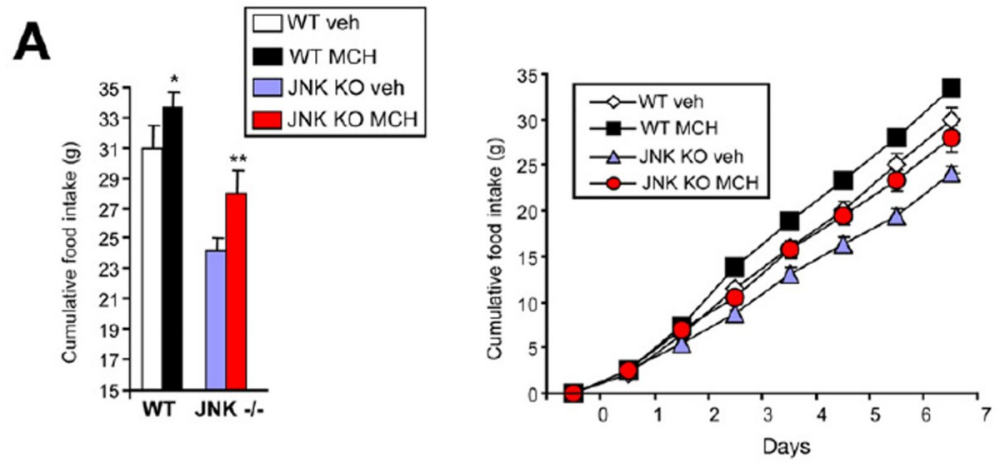

\section{B}
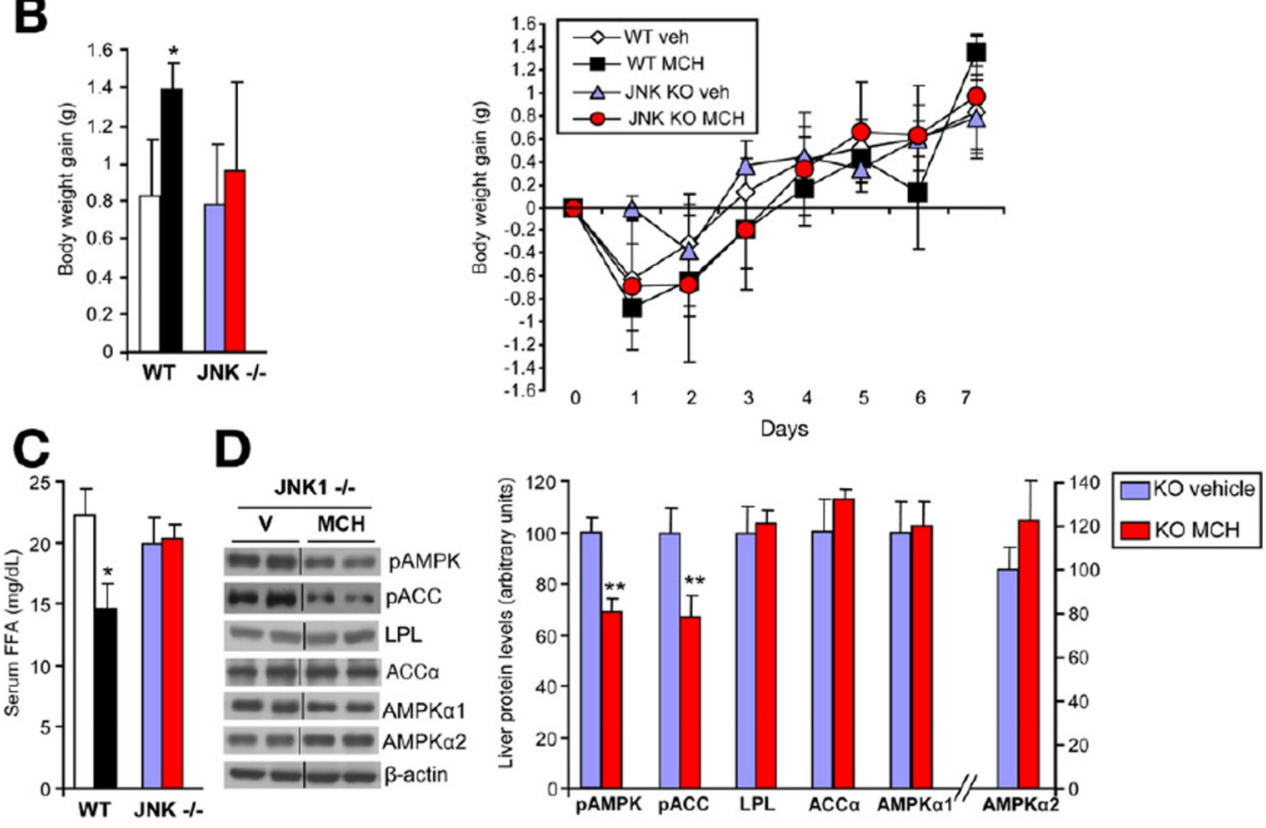

E

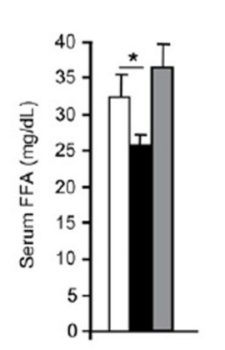

$\mathbf{F}$

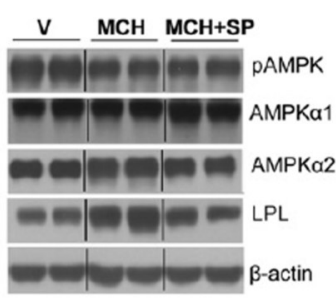

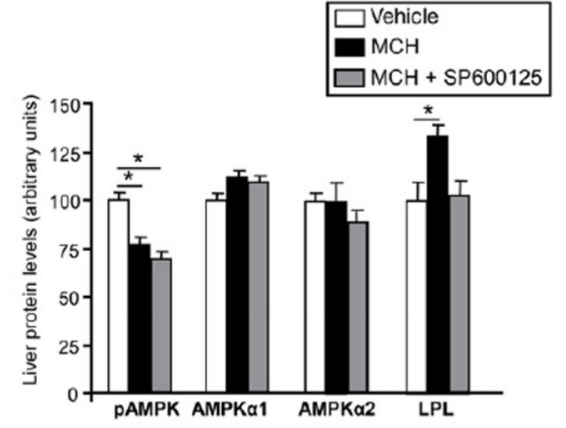

Figure 6.

Effect of a 7-day ICV MCH (2.5 $\mu \mathrm{g}$ /day) infusion on ( A) cumulative food intake; ( B) body weight gain; ( $\mathrm{O}$ serum FFA levels in WT and JNK1 KO mice; and ( D) liver protein levels of pAMPK, pACC, LPL, ACC $\alpha$, AMPKa1, and AMPKa 2 in JNK1 KO mice. Effect of a 6day ICV MCH (2.5 $\mu \mathrm{g} /$ day) infusion + IP SP600125 (JNK inhibitor) treatment on (E) serum FFA and ( $B$ liver protein levels of pAMPK, AMPKa1, AMPKa 2, and LPL. $\beta$-actin was used to normalize protein levels. Values are mean \pm standard error of the mean of 6-8 animals per group. ${ }^{*} \mathrm{P}<.05$ and ${ }^{* *} \mathrm{P}<.01$ vs controls. 
A

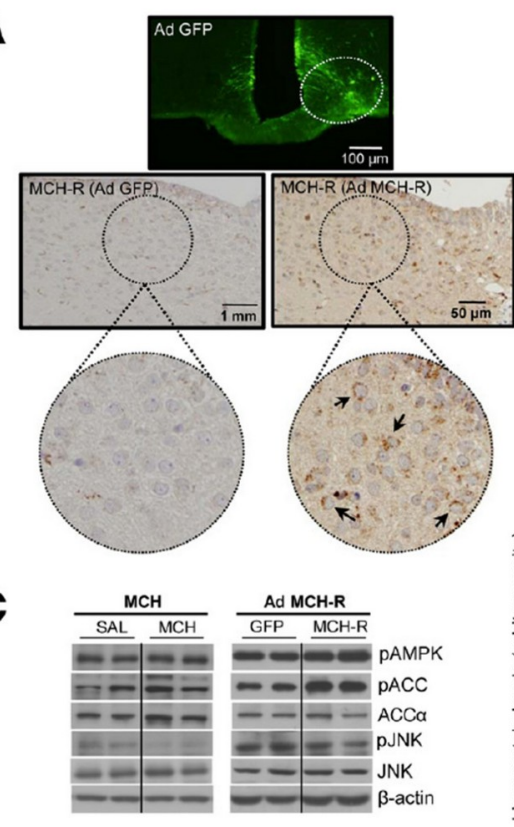

D
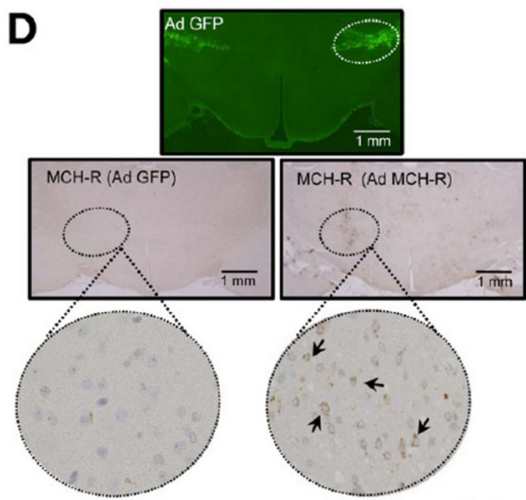

$\mathbf{F}$

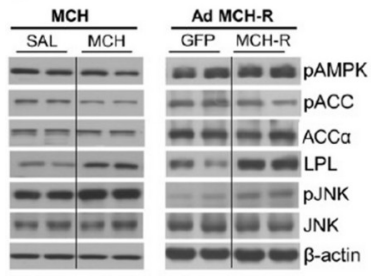

B
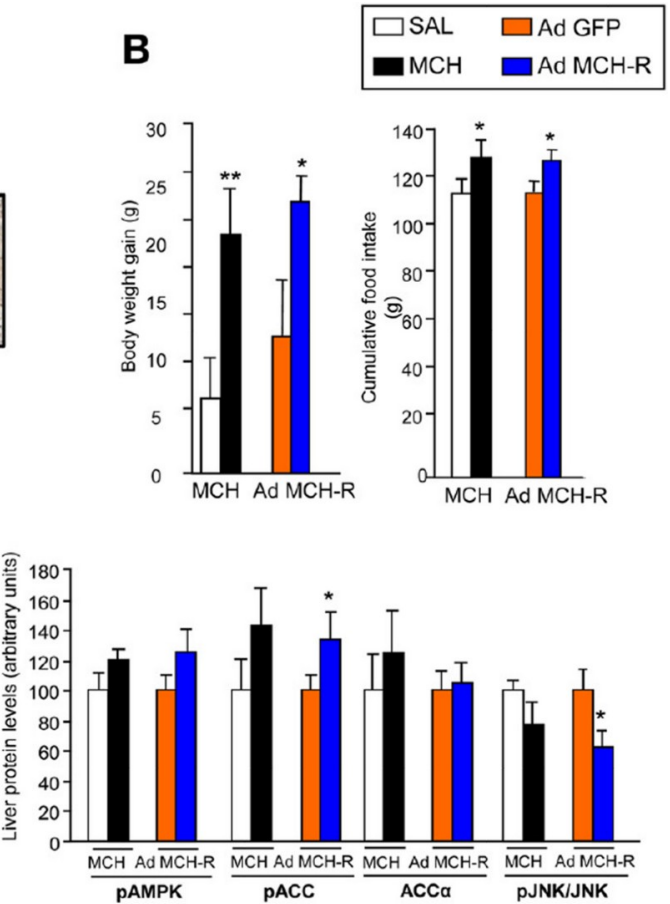

E

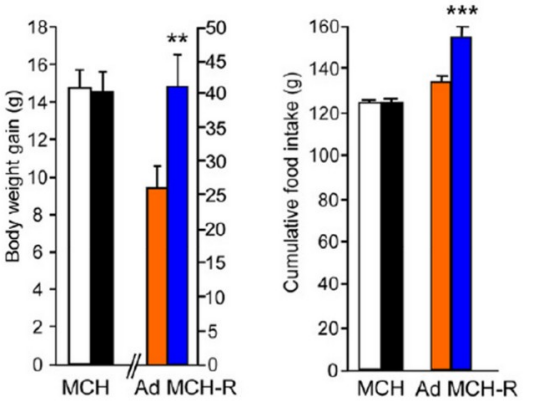

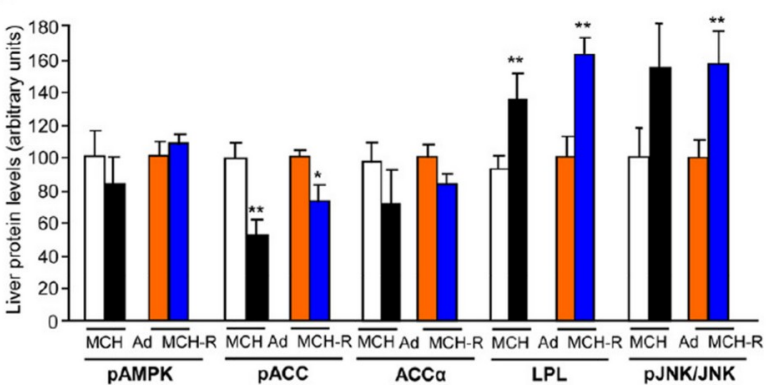

Figure 7.

( A) Localization studies of microinjection sites, showing the immunofluorescence with antiGFP antibody in the ARC ( upper panelland the immunohistochemistry of MCH-R in rats treated with a GFP- or MCH-R-expressing adenovirus in the ARC ( lower pane)! ( B Body weight change and cumulative food intake and ( $\mathrm{O}$ protein level profiles in liver of rats treated stereotaxically with a GFP- ( orangł or MCH-R-expressing adenovirus ( bluæ in the ARC. ( B) Body weight change and cumulative food intake and ( $O$ protein level profiles in liver after a 7-day infusion of saline ( whitł orMCH (6 $\mu \mathrm{g} /$ day) (black specifically into the ARC. ( D) Localization studies of microinjection, showing the immunofluorescence with anti-GFP antibody in the LHA ( upper panelland the immunohistochemistry of MCH-R in 
rats treated with a GFP- or MCH-R-expressing adenovirus in the LHA ( lower panell ( E) Body weight change and cumulative food intake and (B) protein level profiles in liver of rats treated stereotaxically with a GFP- ( orang£ or MCH-R-expressing adenovirus ( blù in the LHA. ( E) Body weight change and cumulative food intake and ( $\mathrm{B}$ protein level profiles in liver after a 7-day infusion of saline ( whit) or MCH (6 $\mu \mathrm{g}$ /day) (black specifically into the LHA. $\beta$-actin was used to normalize protein levels. Values are mean \pm standard error of the mean of $7-8$ animals per group. ${ }^{*} \mathrm{P}<.05$, ** $\mathrm{P}<.01$, and ${ }^{* * *} \mathrm{P}<.001$ vs controls. 